\title{
Supplier dependence and innovation: A contingency model of suppliers' innovative activities
}

\author{
Rajan R. Kamath \\ College of Business Administration, University of Cincinnati, Cincinnati, OH 45221-0165, \\ U.S.A. \\ Jeffrey K. Liker \\ Industrial and Operations Engineering, The University of Michigan, Ann Arbor, MI 48109, \\ U.S.A.
}

\begin{abstract}
The management of innovation is a complex task and the management of suppliers' innovative activities is especially so because it involves managing technological factors across the traditional boundaries of the firm. This paper explores the determinants of suppliers' innovative activities by developing a theoretical model of these activities and testing this model with data from a set of organizations that supply intermediate goods to the automotive Original Equipment Manufacturers (OEMs) in the United States. The contingency model developed assumes that the factors influencing product innovation by a supplier firm depend on a key characteristic of its environment - the degree of dependence on a specific automotive OEM for its livelihood. Statistical analysis of survey data on supplier innovative activity from 172 respondents demonstrates that there are substantial differences in the factors leading to innovative activity in independent and dependent suppliers. While independent suppliers follow more traditional economic models which argue that they will innovate only if they perceive favorable and calculable benefit-cost ratios, dependent suppliers seem more willing to innovate in less clearly favorable circumstances if they are clear on what kinds of innovations are desired by their customers. That is, the dependent suppliers are willing to invest in innovation to maintain their customer base even if the results are not clearly cost effective in the short term. The implications are that OEMs that place a high priority on encouraging innovation by their suppliers must make some effort to differentiate between suppliers that are highly dependent on the OEM-supplier relationship and those that are not. The study results suggest ways in which these two types of suppliers should be managed.
\end{abstract}

Keywords. Innovation, Manufacturer-supplier relations, R\&D strategy.

\section{Introduction}

In the manufacturing sector, the suppliers of intermediate goods deliver parts, components and sub-assemblies to Original Equipment Manufacturers 
(OEMs) who incorporate these items into the final assembly of the finished product. The innovative activities of these suppliers have a substantial impact on the competitive position of the OEMs because the innovative output of these suppliers can be incorporated into the OEM's final product so as to yield competitive advantage. Across the globe, OFMs are making a renewed effort to understand and manage the innovative activities of their suppliers (Morgan, 1986; Mullins, 1985; Gooding, 1986; Sanger, 1987; Flynn, 1986; Shapiro, 1985).

The management of innovation is a complex task and the management of suppliers' innovative activities is especially so because it involves managing technological factors across the traditional boundaries of the firm. This paper explores the determinants of suppliers' innovative activities by developing a theoretical model of these activities and testing this model with data from a set of organizations that supply intermediate goods to the automotive OEMs in the United States. The model, based on contingency theory (Lawrence and Lorsch, 1969), distinguishes suppliers that are heavily "dependent" on an automotive OEM for their livelihood and those that are more diversified across several automotive OEMs or into non-automotive business and are thus more "independent" and demonstrates that there are substantial differences in the factors leading to innovative activity in these two cases.

\section{Research question}

Previous research suggests that the innovative activities of suppliers are driven by forces that are derived from the industry environment within which the supplier operates, and forces that grow out of the specific buyer-supplier relationship that has developed between the buyer and the supplier firm (Kamath, 1988). The research literature in economics (Kamien and Schwartz, 1982) provides us with the theoretical infrastructure to understand the role of the industry environment and the research literature in resource dependence (Pfeffer and Salancik, 1978) and engineering management (Von Hippel, 1982) sheds some light on the role of the buyer-supplier relationship. While the resource dependence model emphasizes the role of dependence in inter-organizational relationships, very little is known about the influence of dependence on innovation.

The few practitioners who have studied suppliers' innovative activities (Burt and Soukup, 1985) write about product development as a cooperative venture between the buyer firm and suppliers. However, such studies usually sum up their conclusions by calling for the timely involvement of all vendors in the design process of the buyer firm. This state of affairs leaves many vital questions unanswered: Is involvement in the buyer's design process the only factor under the control of the buyer? Can the buyer firm manage the buyer-supplier interface in order to influence the supplier's innovative activities? Should vendor management policies be applied uniformly to dependent as well as inde- 
pendent suppliers? This paper addresses the research question: How does the supplier's dependence on the OEM influence the innovative activities of the supplier?

In order to address this issue we construct a theoretical model of the supplier's innovative activities and develop a theoretical explanation of the influence of dependence on innovation through a synthesis of existing theory and the first-hand experiences of the executives of supplier firms. The anecdotal component of this synthesis is a direct result of the rich information on buyersupplier relations obtained during the data collection and pretest efforts for the Automotive Supplier Innovation Project (Kamath et al., 1988). The driving force behind our choice of this research issue and our approach to theory building and testing is the desire to put into place the building blocks which may eventually lead to a bona fide theory of the relationship between dependence and innovative activity.

\section{Theoretical model}

The underlying theoretical framework that we apply in this study is contingency theory. That is, the model assumes that the forces that govern the supplier's innovative activities are situationally determined. Moreover, we take an open-systems perspective and argue that to a substantial extent these forces can be found outside the firm in their competitive environment (Lawrence and Lorsch, 1969).

It is one thing to assert that a phenomenon is situational and quite another to specify what situations lead to particular causal relationships. In order to do this we draw on a combination of economic theory and organization theory. We argue that under certain conditions, the economic variables will be key in determining the quantity and nature of innovative activity and under other conditions organizational factors will be key. To be specific, our theoretical model proposes that the innovative activities of supplier firms that are not dependent on a particular buyer firm are more likely to be driven by calculable potential benefits of innovation. By contrast suppliers that are dependent on a particular buyer firm are more willing to invest in innovation even when direct calculated benefits do not exceed costs as long as they are clear about the customers needs, referred to below as the clarity of innovation objectives. Thus, their innovative activity depends more on the strength of the interorganizational communication links with their customers. We elaborate below on the definitions of potential benefits of innovation and clarity of innovation objectives, and our rationale for relegating such a central role in the model to supplier dependence.

\subsection{Potential benefits of innovative activity}

The relationship between technical advance and monopoly power lies at the heart of the Schumpeterian theory of innovation (Schumpeter, 1964, 1975). 
This theory proposes that the innovating firm gains a temporary monopoly position by virtue of the uniqueness of the product it offers. The profits associated with this monopoly position provide the motivation for innovative effort. Naturally, these profits can only be realized if imitation by rivals can be limited or prevented altogether. The crux of the argument is that firms that perceive the potential for substantial monetary return from the ownership of proprietary technology are more likely to engage in innovation than those that do not. The empirical support for this line of argument has not been strong (Horowitz, 1962; Hamberg, 1966; Scherer, 1967; Comanor, 1967; Finet, 1975) and some researchers have suggested that whereas there are arguments in favor of the view that monopolistic elements are conducive to innovation, there are also powerful presumptions that work in the other direction (Kamien and Schwartz, 1982). An effective monopoly will have little or no incentive to innovate and may choose not to take the risks or the trouble necessary to find new ways of operation and to adopt those novel paths.

In reality many industrial innovations are not patented and do not afford the innovating firm the level of protection from competition that would allow a slackening of the innovative efforts. Instead, the typical firm uses innovation to gain temporary differentiation from its competition and depends on continued innovation to maintain its differentiated position in the face of imitation. The economic returns to be gained from this temporary differentiation would depend on the characteristics of the specific technology and the competitive environment in the industry. In situations where the potential benefits of owning proprietary technology are higher the supplier firm is expected to be more willing to engage in innovation. We predicted, therefore, that the relationship between the supplier's innovative activities and the potential benefits of owning proprietary technology (as perceived by decision makers in the supplier firm) will be significant and positive. It is important to note that these potential benefits are determined by the competitive situation in the supplier's industry environment and not by the nature of the interorganizational relationships between the suppliers and their customers.

\subsection{Clarity of innovation objectives}

Researchers who have examined the "sources" of industrial innovation have found consistent support for the crucial role played by the user of the innovation. This stream of research uses terminology in which a "user" uses an innovation but does not manufacture it for sale. The "manufacturer" manufactures an innovative product for sale but does not use it. This is the kind of situation that arises in industries that manufacture capital goods or industries that supply intermediate goods that the OEM then incorporates into the assembly of the finished product. Von Hippel $(1976,1977,1982)$ has organized the research on innovation to highlight the central role of the user in the in- 
novation process. He examines "user-dominated" innovation and demonstrates that organizations that engage in innovation are open systems that import large quantities of their informations needs from the user.

This theory suggests that the buyer-supplier relationship can be seen as a two-way conduit for information that helps the supplier and the OEM clarify the objectives of the supplier's innovative activity. A supplier that has achieved a thorough understanding of the needs of the OEM can use this knowledge as a rich source of information to guide the innovative effort. A firm that faces a technology adoption decision engages in an extensive effort to reduce the uncertainty associated with that decision (McCardle, 1985) and information about the buyer is an important part of this excercise. An OEM that understands the supplier's innovative efforts is better prepared to incorporate the results into the design of the final product. We therefore predicted that the clarity of innovation objectives in an OEM-supplier relationship has a positive and significant association with the supplier's innovative activities.

\subsection{Dependence and innovation}

We begin with the assumption that innovation is expensive in terms of resources and there are several projects that are competing, at any given point of time, for the supplier firm's investment dollar. For example, the supplier firm may invest in expanding existing facilities, or new business development, or make investments directed toward increasing its innovation. In the multibusiness supplier firm the number of competing projects multiply across the various business units. The funds available for investing are never adequate to pursue all the competing projects effectively and suppliers who engage in innovation make the appropriate investments in a conscious and deliberate fashion.

Power and control can be thought of in terms of vulnerability as well as dependence (Jacobs, 1974) and in the context of exchange relationships (Pfeffer and Salancik, 1978) organizational dependence has two components: the essentiality of the item received in the exchange and that item's availability from other sources. In this paper we focus on the proportion of the supplier's total dollar revenues that come from business with the specific OEM in question. The theoretical linkage between dependence and innovation arises from the fact that innovative activity can change the essentially as well as the availability of the item in question. Innovative activity would be attractive to a supplier firm if it could either reduce the firm's dependence on the buyer or if the buyer's dependence on the firm could be increased through innovation. First, the innovative features of the item may, in a competitive sense, make it more important to the buyer. Second, if the innovative features are unique, the availability of the item from other sources is reduced drastically until competing suppliers manage to imitate the innovation. Finally, if the innovative ac- 
tivity has the potential for spin-offs that enlarge the supplier's customer base or facilitate the supplier's entry into new markets the supplier would engage in innovation.

The linkage between innovation and dependence yields the insight that innovation means different things for suppliers that are highly dependent on an OEM-supplier relationship and those that are relatively independent. The dependent supplier views innovation as compliance behavior in situations where the OEM values innovation: complying with the OEM's demands for innovative output is a way of managing a dependence relationship. Additionally, the dependent supplier values the fact that innovation may increase the market attractiveness of the output to new OEM customers which might help reduce the risks associated with dependence on a particular OEM. In contrast, the independent supplier is a diversified firm with a variety of product-market options. This kind of supplier is more likely to evaluate innovative investments from the perspective of the alternate uses of the resources available: innovation is worthwhile if the calculable potential economic returns from innovative activities are significant.

This leads to the two propositions that we investigate in the balance of this paper:

(1) The innovative activities of dependent suppliers are more responsive to the clarity of innovation objectives than those of independent suppliers. Dependent suppliers find innovation attractive for reasons discussed above. When they gain some clarity about the OEM's specific needs and R\&D programs, their innovative activities increase.

(2) The innovative activities of independent suppliers are more responsive to the potential benefits from innovation than those of dependent suppliers. Independent suppliers have well-developed research agendas that are less responsive to the needs of specific OEMs than those of dependent suppliers. When the potential benefits of owning proprietary technology are high, their innovative activities increase.

\subsection{Control variables}

The typical OEM purchases parts, components and sub-assemblies from a large number of suppliers in a variety of different industries. We complete the specification of our model by introducing four control variables that influence innovative activity. The variables are the technological opportunity for innovation in the supplier's industry, the growth prospects within the industry, the intensity of competitive rivalry in the industry and the supplier firm's commitment to innovation. These variables grow out of activity in the scientific base and the competitive situation experienced by the supplier firm.

Technological pportunity. The linkage between technological opportunity and 
innovation is best captured by the thought that developments in basic scientific knowledge open up opportunities for innovation (Phillips, 1966). A firm's manufacturing operations can be visualized in terms of an underlying base of scientific facts and principles. A scientific base that is characterized by major changes taking place in a short period of time gives the firm many opportunities to engage in innovation (Phlips, 1971; Kelly, 1970; Merton, 1973). We expected that the relationship between the supplier's innovative activities and the technological opportunities perceived by the supplier will be positive and significant.

Growth. The central theme with reference to growth is that innovation is a response to profit opportunities. Schmookler (1966) developed this idea by arguing that innovation was an economic activity pursued for gain, and expected gain varies with expected sales of the goods embodying the innovation. Kamien and Schwartz (1982, p. 35) speculated that one would expect growing industries to be generally more innovative than declining ones. We expected that growth will have a positive and significant relationship with the innovative activities of the supplier.

Intensity of competitive rivalry. Braunstein et al. (1980) asserted that only competitive pressures can constantly force innovation, for then each firm must do its utmost to be the first with a better idea for fear of being beaten out by its rivals. Innovative efforts that were perceived to have no competition are characterized by slackened efforts while the perception that the competition was working on a similar effort heightens the pressure on the project team. In an attempt to test the rivalry theory of R\&D spending Hambrick et al. (1983) conducted a longitudinal study of individual business units and showed that growth businesses tend to adjust their $R \& D$ spending based on the innovative 'gap' between the focal business and its competitors. We expected that the supplier's innovative activities have a positive and significant relationship with the direct competition experienced by the supplier firm.

Supplier's commitment to innovation. As the automotive OEMs went about redefining their supplier management policies (Kamath, 1986) they began exerting pressure on suppliers to adopt postures that were akin to those of Japanese automotive suppliers. In general, the postures involved investments that would make the suppliers more responsive to the OEM. These investments ranged over a wide spectrum from appointing special liaison personnel to setting up multi-million dollar dedicated research and engineering facilities in physical proximity to the OEM's assembly plant. We argue that a supplier that has been forced to make a symbolic investment of this sort can be expected to try and use it for increasing innovation. We expected a positive and significant 
relationship between the investments that measure a supplier's commitment to innovation and the supplier's innovative activities.

\section{Research methods}

\subsection{Survey design}

The Manufacturer-Supplier Survey of the Joint U.S.-Japan Automotive Study (Cole et al., 1985) gathered survey data from the Chief Executive Officers of two hundred and forty automotive suppliers. The data for this paper is based on a subsequent survey, the Automotive Supplier Innovation Project (Kamath et al., 1988), conducted in 1987, in which these 240 Chief Executive Officers were sent two copies of a questionnaire along with a letter requesting that their Vice-President of Research and Development (R\&D) and VicePresident of Marketing complete the questionnaires. The questionnaire consisted of 41 questions, both structured and open-ended, dealing with the supplier's innovative activities and their competitive environment. The structured questions asked the respondents to rate dimensions of innovation and the environment on seven-point scales. The data collection effort was aimed at top management because of the ways in which top management exerts its influence on the innovative activities of the firm (Gold, 1986).

During the survey design stage the questionnaire was pretested by three industry experts and members of the Supplier Council at General Motors, CPC Division. Previous attempts at gathering survey data from automotive suppliers (Cole et al., 1985) have encountered three major problems: (1) many automotive suppliers deal in more than one automotive product and the terms "innovation" and "competitive environment" mean different things in different product markets; (2) many automotive suppliers sell to more than one OEM and the nature of OEM-supplier relationships differs widely across these OEM customers; and (3) questions that ask for innovation-related data are often left unanswered because these data are central to the supplier's competitive strategy.

To address these problems the questionnaire cautioned respondents that some survey questions are best answered with a specific product in mind and requested that the respondents deal with such questions with reference to the automotive product that accounted for the largest dollar volume of their sales. Further, the survey requested that respondents deal which such questions with reference to the automotive OEM customer that accounted for the largest dollar volume purchase of the product identified above. Finally, the questions that dealt with sensitive information - details regarding the intensity and importance of innovative activities - were designed so that respondents could give a subjective rating of these dimensions as compared to the respondent's major 
competitor. This eliminated the need to deal with absolute numbers which may be considered proprietary.

In all, 172 responses were received from 114 companies. A total of 56 of these 114 companies returned 2 questionnaires, each answered by respondents in the Marketing and R\&D functions. The remaining 58 companies returned single questionnaires, and one company returned 3 questionnaires - one from each of three automotive divisions. This yielded a response rate of $36 \%$ measured by the number of questionnaires returned and $47.5 \%$ measured by the number of companies that responded. Extensive telephone follow-up was used to eliminate all the missing data from the responses received so that the final dataset contains 172 responses that are complete in all respects.

\subsection{The key informant technique}

The approach to data collection was based on the key informant technique. In this technique the role of the informant involves giving reports about the patterns of behavior, after summarizing either observed (actual) or expected (prescribed) organization relations (Seidler, 1974). The researcher relies on a small number of knowledgeable participants who observe and articulate relationships for the researcher. Questions consistently ask informants to report in terms of the aggregate level of analysis. Responses are quantified and the data are used to test theoretically deduced hypotheses.

While using the survey respondent approach for organization measures, the aim is to obtain a representative sample of all individuals of each segment of the organization to which the measure applies. With the key informant technique, informants are asked to do the summarizing for the researcher and to think in terms of the organization so the sampling of informants is based on informant perceptions and expertise with respect to the desired organizational measures rather than obtaining a representative sample of a universe of members. Informants are selected because of their thorough knowledge of the area of inquiry and their ability to articulate it.

In an ideal world, researchers may wish to gather data from different multiple informants for each of the constructs under study. For example, certain informants might report on the firm's external relations and others could report on the firm's internal structural characteristics. Moreover, to avoid the biases of self-report it would be desirable to measure some of the key variables, e.g., the measures of innovation, from records of the firm. This approach is time-consuming, expensive and requires extensive pre-survey contact with each organization. Whereas the gains in terms of reliability and validity might well have been worth the costs of this approach, we found, during the pretesting of the questionnaire, the supplier firms were unwilling to make the strong commitments needed. 


\subsection{Construction of variables}

The dependent variable in our model is the amount of innovative activity engaged in by the supplier. We constructed an "Innovative Activity Index" based on four indicators (all measured on a seven-point scale rating themselves relative to competitors ) - the supplier firm's R\&D expenditures as a percentage of sales, the size of the supplier's $R \& D$ team, the innovative capabilities of the supplier firm's R\&D personnel, and the innovative track record of the supplier firm. With an eye toward the ongoing debate about the relative effectiveness of input and output measures of innovation (see Kamien and Schwartz, 1982), we selected the first two indicators so that they measured dollar expenditures and personnel - inputs to the innovation process - and the last two so that they measured outputs of the innovation process. The Innovative Activity Index is based on a weighted average of these indicators. To calculate the weights we did a confirmatory factor analysis, computed the total of the factor loadings, and computed the weight for each indicator by representing its factor loading as a percentage of the total. The resulting index also ranges from one to seven. The LISREL package was used to do the confirmatory factor analysis that yielded the factor loadings for this index. A similar approach was used for three other variables measured by multiple indicators. The summary statistics of the LISREL model are reported at the end of this section ${ }^{1}$.

Three of the independent variables - Potential Benefits, Clarity of Innovation Objectives and Degree of Technological Change - are also indices that have been constructed by combining more than one indicator in the same way as the indicators for Innovative Activity were constructed. Potential Benefits was constructed out of two indicators - the importance of proprietary products for the supplier's business and the importance of non-patented trade secrets for the supplier's business. Clarity of Innovation Objectives was constructed out of four indicators - the frequency with which the OEM shares R\&D related information, the supplier's understanding of the OEM's need for innovation, the OEM's understanding of the supplier's R\&D and their understanding of the supplier's business. Finally, Degree of Technological Change was constructed out of two indicators - the magnitude and speed of change in the supplier's scientific base. All the constructs in the model, except for Percent Auto Sales and Percent Growth of Market were measured in a seven-point scale ranging from low to high.

In order to assess the reliability and validity of the measures we used confirmatory factor analysis. That is, we included all of the individual indicators of underlying constructs in a LISREL measurement model, along with the assumed measure-construct relationships. and estimated the fit of the specified model using the maximum likelihood estimation procedure of LISREL. In this way we

${ }^{1}$ Detailed LISREL printout is available from the authors on request. 
were able to simultaneously test for reliability of measurement and construct validity by looking at the overall fit of the model. The LISREL run (using the SPSSX package) reported a Chi-square of 90.60 with 71 degrees of freedom and a probability level of 0.058 , a good fit considering the relatively large sample size. Moreover, there was no significant difference in the measure-construct relationships for dependent and independent suppliers. These results provided us with strong evidence of the reliability and validity of the constructed indexes.

One might ask why we report the results of regression analysis below instead of simply presenting the structural model estimated by LISREL. After all LISREL adjusts for measurement error. In this case the LISREL estimates of structural results were virtually identical to the regression results. Thus, we chose to present the results of regression analysis, a method with which we suspect readers are more familiar.

\section{Results}

The 172 cases in the data set were divided into dependent and independent suppliers based on the supplier firm's total automotive sales as a percentage of total worldwide sales: those cases above $60 \%$ were classified as dependent suppliers while those below $60 \%$ were classified as independent. The measure automotive sales as a percentage of total sales was an indicator of the supplier firm's dependence on the automotive segment of its operations. The cut-off at $60 \%$ was selected to divide the total number of cases into two approximately equal groups.

Descriptive statistics for the variables in our model and the correlation matrix for these variables are given in Tables 1 and 2. Table 1 indicates that the dependent and independent sub-groups are not very different along most of the dimensions measured in our model. The only difference approaching significance is on the Growth dimension where dependent suppliers report, on the average, a higher growth rate for their markets than independent suppliers. The correlation matrix in Table 2 demonstrates that the correlations among our independent variables are relatively low (less than 0.30 ) and therefore no significance collinearity problem is evident.

Table 3 presents the results of regression analysis with the Innovation Activity Index as the dependent variable. Separate equations are presented for the total sample, the dependent suppliers only, and the independent suppliers only. Whereas both of the major propositions that we developed in this paper are supported, none of our minor hypotheses (regarding control variables) are supported by the analysis.

For the total sample, both the potential benefit of innovation and the clarity of innovation objectives are associated with high levels of innovative activity. Moreover, as predicted, there are differences in the factors that predict innovative activity for dependent and independent suppliers. Clarity is a highly significant predictor for the sub-group of dependent suppliers and, in terms of 
TABLE 1

Descriptive comparison of dependent and independent suppliers

\begin{tabular}{|c|c|c|c|c|c|}
\hline \multirow[t]{2}{*}{ Variable $^{a}$} & \multicolumn{2}{|c|}{$\begin{array}{l}\text { Dependent } \\
\text { suppliers }(N=84)\end{array}$} & \multicolumn{2}{|c|}{$\begin{array}{l}\text { Independent } \\
\text { suppliers }(N=88)\end{array}$} & \multirow[t]{2}{*}{$t$-Test } \\
\hline & Mean & S.D. & Mean & S.D. & \\
\hline Percent auto sales & $86 \%$ & (12) & $33 \%$ & $(20)$ & 21.5 \\
\hline Potential benefits & 4.5 & $(1.4)$ & 4.6 & $(1.4)$ & -0.7 \\
\hline Clarity objectives & 4.7 & $(0.9)$ & 4.5 & $(1.0)$ & 1.6 \\
\hline Percent growth of market & $12 \%$ & $(23)$ & $7 \%$ & $(15)$ & 1.9 \\
\hline Commitment to innovation & 2.6 & $(2.1)$ & 2.3 & $(2.2)$ & 0.9 \\
\hline Number of competitors & 3.9 & $(1.8)$ & 3.7 & $(1.5)$ & 0.9 \\
\hline Degrec of technological change & 4.7 & (1.4) & 4.6 & (1.4) & 0.5 \\
\hline Innovative Activity Index & 4.5 & $(1.0)$ & 4.3 & (1.3) & 1.2 \\
\hline
\end{tabular}

${ }^{a}$ With the exception of Auto Sales and Growth of Market, all other variables are measured on a seven-point scale ranging from low to high.

TABLE 2

Correlation matrix of independent and dependent variables ( $N=172$ suppliers $)$

\begin{tabular}{llllrlrr}
\hline & & $(1)$ & $(2)$ & $(3)$ & (4) & (5) & (6) \\
\hline Potential benefits & $(1)$ & & & & & & \\
Clarity of objectives & $(2)$ & 0.22 & & & & & \\
Growth of market & $(3)$ & 0.14 & 0.25 & & & & \\
Commitment to innovation & $(4)$ & 0.24 & 0.18 & 0.03 & & & \\
Number of competitors & $(5)$ & 0.05 & -0.06 & -0.07 & 0.04 & & \\
Degree of technological change & $(6)$ & 0.28 & 0.06 & 0.13 & 0.15 & -0.03 & \\
& $(7)$ & 0.33 & 0.24 & 0.04 & 0.15 & 0.01 & 0.17 \\
Innovative Activity Index & & & & & & & \\
\hline
\end{tabular}

magnitude, clarity has by far the strongest effect on the Innovative Activity Index for this subgroup (standardized coefficient $=0.33$ ). On the other hand, Potential Benefits is the only independent variable that is significant for the sub-groups of independent suppliers and, in terms of magnitude, Potential Benefits has the strongest effect on the Innovative Activity Index (standardized coefficient $=0.30$ ). A comparison of the magnitude of the unstandardized coefficients for Potential Benefits and Clarity across equations for dependent and independent suppliers shows statistically significant differences. These results support the argument that dependence has an important role in influencing the supplier's innovative activities. 


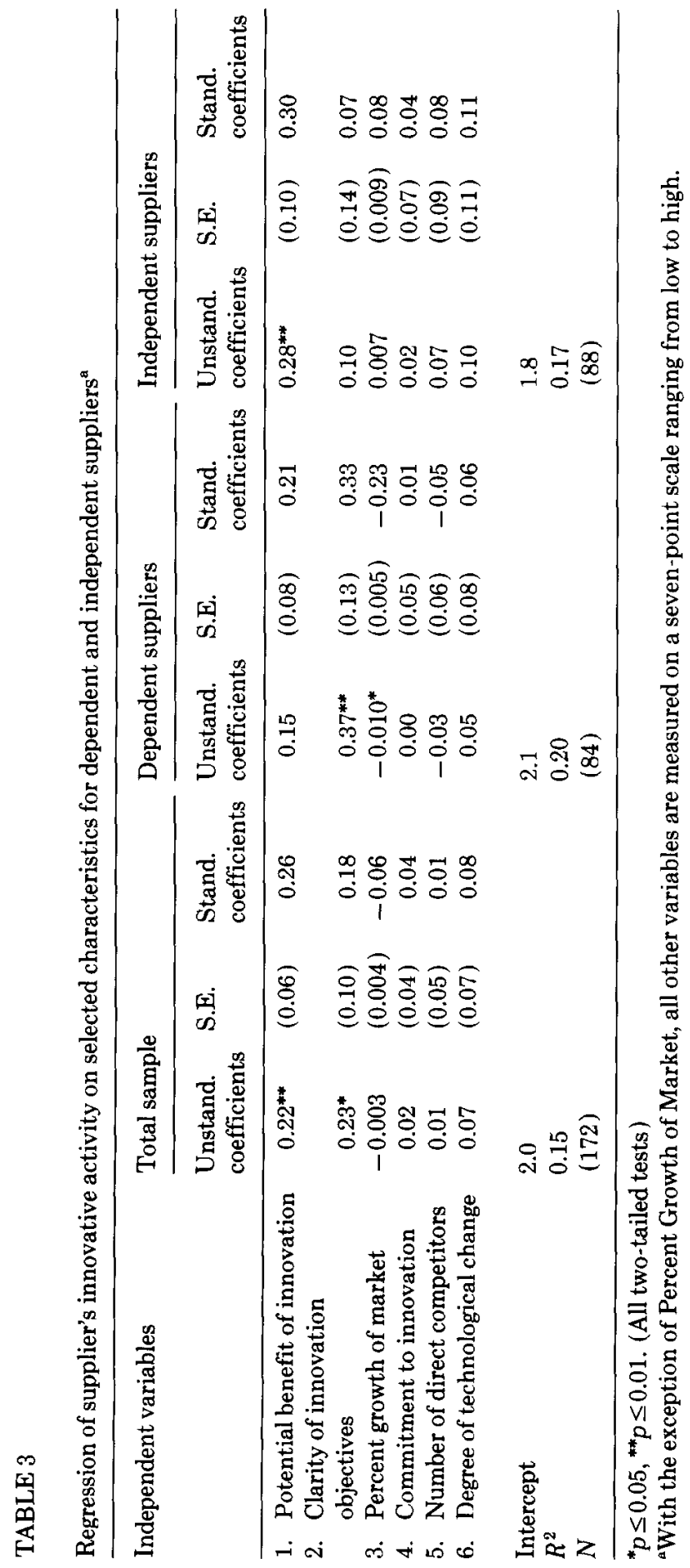




\section{Managerial implications}

The findings of this study highlight the linkage between dependence and innovation, a linkage which has been implicit in the empirical results of several studies (for a review of these studies see Kamath, 1988) but has never been modeled explicitly. Additionally, the results show that the relationship is interactive, not additive. That is, the effects of selected factors are contingent upon the level of dependence of the supplier on the customer. This suggests a path by which OEMs can influence the innovative activities of their suppliers. OEMs have very little control over the market environment within which their suppliers operate. However, they have a major role in the design of the OEMsupplier relationship and the development of a theoretical understanding of the linkage between the OEM-supplier relationship and innovation can have far-reaching implications for the management of OEM-supplier relationships.

If an OEM places a high priority on encouraging innovation by suppliers it must make some effort to differentiate between suppliers that are highly dependent on the OEM-supplier relationship and those that are not. By itself this statement is not very insightful: every purchasing manager knows that the mammoth corporation has to be treated differently than the neighbourhood mom \& pop fabrication shop. The value-added in this study is the identification of specific aspects of the buyer-supplier relationship that would spur innovative activity among different kinds of suppliers. The dependent supplier is likely to be more responsive to measures that enhance the clarity of innovative objectives within a buyer-supplier relationship. In contrast, the independent supplier is likely to be more responsive to actions which increase their perceptions of the potential benefits in proprietary technology. This becomes the basis for developing explicit signals that can be used by the OEM to support and nurture the innovative activities of suppliers.

To enhance the clarity of innovative objectives the buyer needs to participate in the orchestration of two-way information-exchange within the buyersupplier relationship, suppliers must become familiar with the buyer's innovative program in order to define their own research effectively, and OEM's must invest resources in understanding the supplier's capabilities. To improve the potential benefits of owning proprietary technology the buycr nceds to respect the intellectual property of the supplier firm and establish economic rewards for innovative output.

\subsection{Approaches to control}

An interesting by-product of this study is some insight into a novel approach to "control" in OEM-supplier relationships. Historically, there have been two approaches to such control: the first approach, derived from the tenets of industrial organization economics (Porter, 1980), emphasizes the need to un- 
derstand and reduce the supplier's bargaining power while the second approach, derived from descriptive studies of OEM-supplier relations in Japan (Kamath, 1986; Cole and Yakushiji, 1984) emphasizes the use of governance and equity ownership.

This study suggests a third approach - one that is based on metacompetence of the OEM. Metacompetence on the part of top managers responsible for managing the innovative activities of suppliers refer to their ability to manage the context of innovative activities - a skill that is distinctly different from the management of innovation. Managers in an OEM's R\&D department are usually charged with the task of managing innovation. This task can be viewed as tactical in that it involves managing $R \& D$ projects on a day-to-day basis. The metacompetence that we refer to operates at a higher level of abstraction because it is outside the arena of routine $R \& D$ decisions: it is a strategic activity that grows out of the manager's ability to evaluate the role of the environmental forces driving a supplier's innovative activities and make decisions to manipulate some of these forces with the objective of boosting the innovative activities of the supplier. Our results seem to indicate that understanding the concepts of Clarity and Potential Benefits as they relate to the level of dependence of suppliers could be a first step toward developing a theory of metacompetence for OEMs that wish to influence supplier's innovative activities.

\subsection{U.S.-Japan comparisons}

In the current economic environment top management must use technological innovation skillfully in order to keep pace with aggressive competitors across the globe. The competitive success of Japanese players in several global markets has drawn the attention of researchers to OEM-supplier relationships between Japanese OEMs and their suppliers. When researchers compare OEMsupplier relationships in Japan and the U.S. and examine the impact of these relationships on innovation (Liker and Kamath, forthcoming, 1991) they suggest that OEM-supplier relationships in the U.S. are based on a rational-economic model where rational decisions taken in the pursuit of economic objectives can lead to arm-lengths, adversarial relationships that suppress the suppliers' innovative activitics. On the other hand, OEM-supplicr relationships in Japan are based on a more cooperative model where rational decisions taken in the pursuit of longer-term interests lead to cooperative, long-term relationships that encourage the suppliers' innovative activities. 'These studies suggest the need for U.S. OEMs to move toward the cooperative model in order to encourage innovation by suppliers.

The model that we have developed in this paper seems to suggest that independent suppliers that innovate to achieve economic benefits may be better understood in terms of the rational-economic model while dependent suppliers are probably more in tune with the major themes of the cooperative model for 
managing OEM-supplier relationships. Any attempt to blindly replicate the Japanese OEM-supplier relationship within the U.S. overlooks the fact that the independent suppliers might not be managed effectively by using the cooperative model - the context of their innovation-related decisions is economic in character and they pursue short-term interests. Even in the case of dependent suppliers, attempts to gain control through equity ownership and longterm contracts may actually be redundant because their dependence situation demands political compliance. In summary, while descriptive comparisons across societies are useful tools for comparative analysis, these comparisons must be complemented by the development of empirically verified theoretical models before they can become the basis for action plans. This paper provides a modest step in that direction.

\section{Acknowledgement}

This research was made possible, in part, by grants from the National Association of Purchasing Management and the Office for the Study of Automotive Transportation (University of Michigan).

\section{References}

Braunstein, Y.M., Baumol, W.J. and Mansfield, E., 1980. The economics of research and development. In: B.V. Dean and J.L. Goldhar (Eds.), Management of Research and Inuovation. (Studies in Management Sciences, 15). North-Holland, Amsterdam, pp. 19-32.

Burt, D.N. and Soukup, W.R., 1985. Purchasing's role in new product development. Harv. Bus. Rev., September-October: 90-97.

Cole, R.E., Flynn, M.S. and Kamath, R.R., 1985. Participants' report on a survey of the North American automotive supplier industry. Industrial Technology Institute, Ann Harbor, MI.

Cole, R.E. and Yakushiji, T., 1984. The joint U.S.-Japan automotive study. Center for Japanese Studies, University of Michigan, Ann Arbor, MI.

Comanor, W.S., 1967. Market structure, product differentiation and industrial research. Q. J. Econ., 81:639-657.

Finet, P., 1975. Determinants de la recherche-developpement industrielle en Belgique. Rech. Econ. Louvain, 41: 51-61.

Flynn, M.S., 1986. Automotive industry engineering outsourcing: Implications for Michigan. Industrial Technology Institute, Ann Arbor, MI.

Gold, B., 1986. Some empirical perspectives on the economic effects of technological innovations. Omega, 14 (2): 99-118.

Gooding, K., 1986. Vehicle components. Financial Times, April 4.

Hamberg, D., 1966. R\&D: Essays on the Economics of Research and Development. Random House, New York.

Hambrick, D.C., MacMillan, I.C. and Barbosa, R.R., 1983. Business unit strategy and changes in the product of R\&D budget. Manage/Sci., 29 (7): 757-769.

Horowitz, I., 1962. Firm size and research activity. South, Econ. J., 28: 298-301.

Jacobs, D., 1974. Dependency and vulnerability: An exchange approach to the control of organizations. Admin. Sci. Q., 19 (1): 45-59. 
Kamath, R.R., 1986. OEM-supplier relations in the automotive industry: Will the Japanese model work for U.S. OEMs? Paper presented at the Annual Meeting of the Academy of Management, Chicago, August 13-16.

Kamath, R.R., 1988. The management of suppliers' innovative activities. Ph.D. dissertation, Graduate School of Business Administration, University of Michigan, Ann Arbor, MI.

Kamath, R.R., Cole, R.E. and Flynn, M.S., 1988. Participant report: Automotive supplier innovation project. Office for the Study of Automotive Transportation, University of Michigan, Ann Arbor, MI.

Kamien, M.I. and Schwartz, N.L., 1982. Market Structure and Innovation. Cambridge University Press, Cambridge.

Kelly, T.M., 1970. The influence of firm size and market structure on the research efforts of large multiple-product firms. Ph.D. Dissertation, Oklahoma State University.

Lawrence, P.R. and Lorsch, J.W., 1969. Organization and Environment. Irwin, Homewood, IL.

Liker, J.K. and Kamath, R.R., forthcoming, 1991. Manufacturer-supplier relations and product design in the U.S. and Japan auto industries. In: D. Kocaoglu (Ed.), Handbook of Technology Management. John Wiley \& Sons, New York.

McCardle, K.F., 1985. Information acquisition and the adoption of new technology. Manage. Sci., 31 (11): 1372-1389.

Merton, R.K., 1973. The Sociology of Science. University of Chicago Press, Chicago, IL.

Morgan, I.P., 1986. The purchasing revolution, IMEDE Perspectives for Managers, 7.

Mullins, P.J., 1985. Shouldering part of the OEM's burden. Chilton's Automot. Ind., 165 (2): $91-$ 92.

Pfeffer, J. and Salancik, G.R., 1978. The External Control of Organizations: A Resource Dependence Perspective. Harper \& Row, New York.

Phillips, A., 1966. Patents, potential competition, and technical progress. Am. Econ. Rev., 56: 301-310.

Phlips, L., 1971. Effects of Industrial Concentration: A Cross-Section Analysis for the Common Market. North-Holland, Amsterdam.

Porter, M.E., 1980. Competitive Strategy: Techniques for Analyzing Industries and Competitors. The Free Press, New York.

Sanger, D.E., 1987. A peek at IBM's trump card. New York Times, March 8.

Scherer, F.M., 1967. Market structure and the employment of scientists and engineers. Am. Econ. Rev., 57: 524-531.

Schmookler, J., 1966. Invention and Economic Growth. Harvard University Press, Cambridge, MA.

Schumpeter, J.A., 1964. Business Cycles. McGraw-Hill, New York.

Schumpeter, J.A., 1975. Capitalism, Socialism and Demorracy. Harper \& Row, New York.

Seidler, J., 1974. The key informant technique. Am. Sociol. Rev., 39: 816-831.

Shapiro, R.D., 1985. Toward effective supplier management: International comparisons. Working Paper No. 9-785-062, Harvard Business School. Cambridge. MA.

Von Hippel, E., 1976. The dominant role of the user in the scientific instrument process innovation. Res. Policy, 5: 212-239.

Von Hippel, E., 1977. The dominant role of the user in semiconductor and electronics subassembly process innovation. IEEE Trans. Eng. Manage., EM-24 (2): 60-71.

Von Hippel, E., 1982. Appropriability of innovation as a predictor of the source of innovation. Res. Policy, 11 (2): 95-115. 